\title{
ECOLOGICAL ASSESSMENT OF EXECUTIVE DYSFUNCTION IN ANXIETY
}

\author{
Flávia Ferreira ${ }^{1}$, Luís Monteiro ${ }^{1,2,3}$
}

Clin Biomed Res. 2018;38(1):22-29

1 Instituto de Investigação e Formação Avançada em Ciências e Tecnologias da Saúde (IINFACTS). Gandra, Portugal.

2 Instituto Universitário de Ciências da Saúde (IUCS), Cooperativa de Ensino Superior Politécnico e Universitário (CESPU). Gandra, Portugal.

3 Grupo NeuroGen, Centro de Investigação em Tecnologias e Serviços de Saúde (CINTESIS). Porto, Portugal.

Corresponding author:

Luís Monteiro

luismc.monteiro@iucs.cespu.pt Instituto Universitário de Ciências da Saúde (IUCS), Cooperativa de Ensino Superior Politécnico e Universitário (CESPU)

Rua Central de Gandra, 1317 4585-116, Gandra, Portugal.

\section{ABSTRACT}

Introduction: The specialized literature states that anxiety can interfere with cognition, particularly in complex cognitive processes such as those related to executive functioning. Neuropsychological studies in anxiety disorders have confirmed the presence of deficits in executive functions, with significant changes in its components. The main aim of this study was to compare the executive performance of a sample with anxiety disorder to a control group, using an instrument that differs from the others by high ecological validity, revealing a higher predictive evidence on daily tasks.

Methods: This study included 60 participants aged between 18 and 53 years that were allocated to an experimental group $(n=30$; mean $=31.93$; standard deviation $[S D]=10.99)$ and a control group $(n=30 ;$ mean $=29.63$; $S D=9.07)$. Anxiety symptoms and the executive functioning were assessed using the Beck Anxiety Inventory (BAI) and the Behavioural Assessment of the Dysexecutive Syndrome (BADS), respectively.

Results: Participants with anxiety disorders presented a significant impairment on executive functioning in general. However, we found a significant impact in tasks that involve control inhibition, design of action strategies according to the functionality and probability of success, the ability to predict or estimate and the ability to plan the action. In addition, the EG required significantly more time to execute all the tests $($ mean $=440.33, S D=97.17)$, compared to the CG $($ mean $=320.90 ; S D=51.27)$.

Conclusions: Individuals with anxiety disorders have a significant impairment in their executive functioning in general, which is reflected in activities of daily living.

Keywords: Anxiety disorders; executive functions; BADS; cognitive and affective evaluation

Anxiety disorders (AD) are one of the most common mental disorders ${ }^{1,2}$, affecting $33.7 \%$ of the population during their lifetime ${ }^{3}$. Anxiety is a natural and perfectly adaptive phenomenon that can be defined as a complex cognitive, affective, physiological and behavioral response system which is activated when anticipated events or circumstances are deemed to be highly aversive because they are perceived to be unpredictable or uncontrollable events that could potentially threaten the vital interest of an individual ${ }^{4}$. However, it is the intensity of anxiety that determines the difference between normal and pathological states ${ }^{5}$. Anxiety and fear are recognized to be pathological when they are exaggerated, disproportional to the stimulus or qualitatively different from what is observed as a norm in that age group and when they interfere with the individual's quality of life, emotional comfort, or daily life performance ${ }^{6}$.

The importance of anxiety in the cognition field lies on its usual association with adverse effects on the performance of cognitive tasks ${ }^{7}$, with both the anxiety state and trait having these effects on complex cognitive tasks ${ }^{8}$. Neuropsychological studies in the literature have demonstrated the presence of deficits in executive functioning $(E F)^{9-11}$, which involves a variety of higher-order cognitive processes ${ }^{12,13}$ that are probably the most complex aspect of human cognition $^{14}$. Most authors considered that EF does not correspond to a unique cognitive ability, but rather to a set of competencies ${ }^{15,16}$ related to production, supervision and behavioral control. These competencies work for specific objectives ${ }^{17,18}$ involving operational memory, selective attention, planning and problem solving, cognitive flexibility, inhibition control, and decision-making ${ }^{19}$. 
EF includes the ability to initiate actions, plan and predict ways to solve problems, bring consequences and modify strategies in a flexible way, with frontal lobes being essential for these processe ${ }^{19}$, particularly the prefrontal cortex (PFC) ${ }^{20}$. However, according to the specialized literature, anxiety is linked to the amygdala and to PFC dorsal and ventromedial areas $^{21}$. There is an increase in amygdala activation and a decrease in activity in the left and right PFC, which is related to deficits in the emotional system ${ }^{22}$. At the neurobiological level, anxiety allows a quick detection and response to the threat, which is an evolutionarily significant aspect of automatic self-regulation. However, high levels of fear may lead to a biased processing toward limbic centers in order to facilitate faster behavioral responses, a process that may inhibit prefrontal cortical function ${ }^{23}$. When anxiety is excessive, attention may be altered, making it difficult to plan and execute long-term goals and increasing the performance of behaviors guided by immediate goals ${ }^{24}$. Recently, the study of Park et al. ${ }^{25}$ endorsed this observation, suggesting that anxiety seems to be associated with PFC hipoactivity by disrupting its activity and suppressing the spontaneous activity of PFC neurons, which could create executive deficits.

Given these important evolutionary and neurobiological connections between anxiety and EF, several studies were interested in analyzing the influence of anxiety on the performance of many cognitive tasks, including those specific to executive functioning, such as task switching, inhibition, problem solving, spatial recognition and memory work, motor initiation and execution task ${ }^{9-11}$ and all of these studies confirmed that anxiety was significantly predictive of worse executive performance. Likewise, a population-based study with individuals from 20 to 64 years was in agreement with the previous studies, pointing out the existence of deficits in $E F$ in general $A D^{26}$. To explain this phenomenon, other researchers proposed that the relationship between anxiety and EF reflects a tendency to divert attention away from the focus of the task toward anxiety-inducing stimuli (e.g. worrying thoughts) while in a state of anxiety?

Although empirical evidence reveals deficits in $E F$ in individuals with $A D$, we found that the neuropsychological instruments commonly used in studies of this nature have low ecological validity, that is, they have an excessively artificial and structured nature, not reflecting properly real-life requirements, where dysfunctions are felt ${ }^{27}$. We know that the characterization and measurement of changes at the executive level constitutes a major challenge to modern neuropsychology ${ }^{28}$. However, the Behavioural Assesssment of the Dysexecutive Syndrome (BADS) combines a solid theoretical basis with adequate psychometric bases for EF evaluation ${ }^{29}$. This battery of neuropsychological tests is recognized as a sensitive measure to deficits associated with prefrontal lobe dysfunction ${ }^{30,31}$ and has been used in many contexts such as schizophrenia ${ }^{32}$, attention deficit hyperactivity disorder ${ }^{33}$, recurrent criminal behavior ${ }^{34}$, depressed and suicidal patients ${ }^{35,36}$, and addictive behaviors ${ }^{37}$. In all these studies, BADS has demonstrated good predictive accuracy in the evaluation of EF.

This research aimed to assess EF in patients with $A D$, using a neuropsychological battery with high ecological validity, and analyze whether there is a variation between executive performance and the severity of anxiety symptoms.

\section{METHODS}

The sample was composed of 60 participants aged between 18 and 53 years, of both genders, allocated in two groups, the experimental group (EG) and the control group (CG). The EG included 30 participants with $A D$, aged between 19 and 53 years ( mean $=31.93$, standard deviation $[S D]=10.99)$. Sample selection was applied an inclusion criteria, through the application of the Beck Anxiety Inventory (BAI) (with a cut-off point of 7 , according to the Portuguese normative values) and the exclusion criteria were pharmacological and/or psychotherapeutic treatments before neuropsychological assessment; comorbid psychiatric diseases, e.g. depression, attention-deficit hyperactivity disorder; physical, mental or sensory impairment; history of neurologic disease; consumption of alcohol and/or drugs. The CG included 30 healthy participants, aged between 18 and 49 years (mean $=29.63, S D=9.07$ ), and excluded those with history or presence of anxiety and/or depression; other psychiatric or neurological diseases; physical, mental or sensory impairment; consumption of alcohol and/or drugs.

The sample was recruited from the student support department at the psychology consulting service of Instituto Universitário de Ciências da Saúde (IUCS). The EG was composed of outpatients who sought for psychology consultation and presented higher BAI scores than the cut-off point. The diagnosis of the EG was made through a semi-structured interview and the DSM-5, to ensure that individuals presented criteria compatible with AD. These participants were identified before the initiation of the psychological intervention.

The CG included students who did not seek consultation and obtained lower BAl scores than the cut-off point. 
Since there is no evidence of an evaluation of EF in AD through the application of the BADS, this is a pilot study that aims to investigate whether we can find the same results through a neuropsychological battery with a higher ecological validity. We are also aware that there is a great difficulty to find a significant sample of patients with the various types of $A D$; thus, we only collected individuals who had significant symptoms in BAI and DSM-5 compatible with AD. In addition, patients who search for psychology consultation usually require immediate psychotherapy and psychopharmacologic intervention to control the symptoms; and, according to the literature, these factors would interfere with the neuropsychological results of our sample. Thus, it was crucial to ensure that our sample was as unbiased as possible with regard to these variables. In a future study, we would like to continue research and investigate the same project assumptions in the various types of AD.

The anxiety symptoms were assessed with the BAI, created by Beck et al ${ }^{38}$. This instrument includes 21 items that reflect somatic, emotional and cognitive characteristics of anxiety ${ }^{38,39}$, constituting a measure that has been carefully designed to avoid confusion with depression. BAI items present an accuracy of 0.99 (value corresponding to the Cronbach's alpha) and a reliability of 0.79 , values that are considered adequate. BAI was validated for the Portuguese population by Quintão $0^{40}$ and consists in a self-reported scale for measuring anxiety intensity, through descriptive statements of anxiety rated on a 4-point Likert scale (0-3). The score ranges from 0 to 63 and makes it possible to classify anxiety into different intensity levels, with a higher score representing a higher anxiety level ${ }^{38,39}$. The interpretation of the results is based on the following ratings: 0 to 7 - minimum anxiety; 8 to 15 - mild anxiety; 16 to 25 - moderate anxiety; 26 to 63 - severe anxiety. For the assessment of EF the Behavioural Assesssment Dysexecutive Syndrome (BADS), developed by Wilson et al. ${ }^{29}$, was administered. It consists of six subtests with activities that simulate real life activities designed to diagnose the existence of deficits in EF in general or in specific components, being sensitive to assess problem solving, planning and intentional organization over extended periods. The administration of the subtests were presented in the following order: Rule Shift Cards (to assess the ability to change the set response pattern); Action Program (solving a practical problem); Key Search (design action strategies according to the functionality and probability of success); Temporal Judgment (ability to predict or estimate how long it takes, on average, to perform various events or day to day tasks); Zoo Map (planning action); and Simplified Six Elements Test (planning, temporal organization of tasks and self-monitoring of the performance). BADS is validated for the Portuguese population by Barbosa et al. ${ }^{41}$ and allows the calculation of a profile score ranging from 0 to 4 point and a global score ranging from 0 to 24 points. The time to execute each subtest was recorded, as well as total time to execute BADS, contributing for the purpose of listing in each of them, except in temporal judgment subtest, where there is no time ${ }^{29}$.

The study protocol was developed in partnership with the IUCS, which allowed the patients who did the first psychology consultation could be recruited to the study. The selection process was properly controlled through a semi-structured interview that also collected socio-demographic variables such as age, socioeconomic level, years of education, all of which were matched in both groups.

An informed consent was obtained from all participants to ensure that ethical principles related of the study objectives, procedures, confidentiality and voluntary participation were safeguarded and that the objectives of this study did not include invasive procedures.

All instruments were administered individually in both groups for an average of one hour in a space with proper conditions (individual, reserved, clean, and free of distractions).

The statistical processing of the data was done through the Statistical Package for Social Sciences (SPSS) software, version 23. In addition to central tendency, dispersion measures (means and standard deviations), and frequency distribution for the socio-demographic data, a parametric Student $t$ test was performed for independent samples to verify the differences between the mean values for $E G$ and $C G$ with $n>30$ for performance of executive functioning. A multivariate analysis was also conducted to study the effect of anxiety level in the dependent measures obtained (BADS total time and score) reporting a significant level of $p \leq 0.05$. When necessary, multiple comparison were made through post-hoc analysis with the Holm-Sidak test, because it presents greater robustness than the Tukey or Bonferroni tests and has been recommended as the first-time procedure for multiple comparison ${ }^{42}$.

\section{RESULTS}

The results obtained can be observed through the analysis of global scores (Figure 1) and through a split analysis for each BADS subtest (Tables 1 and 2 ), regarding the score and time of execution of both groups. In Figure 1, on the left, we present central and dispersion tendency measures with mean values and standard deviations with respect to the overall results of executive performance for 


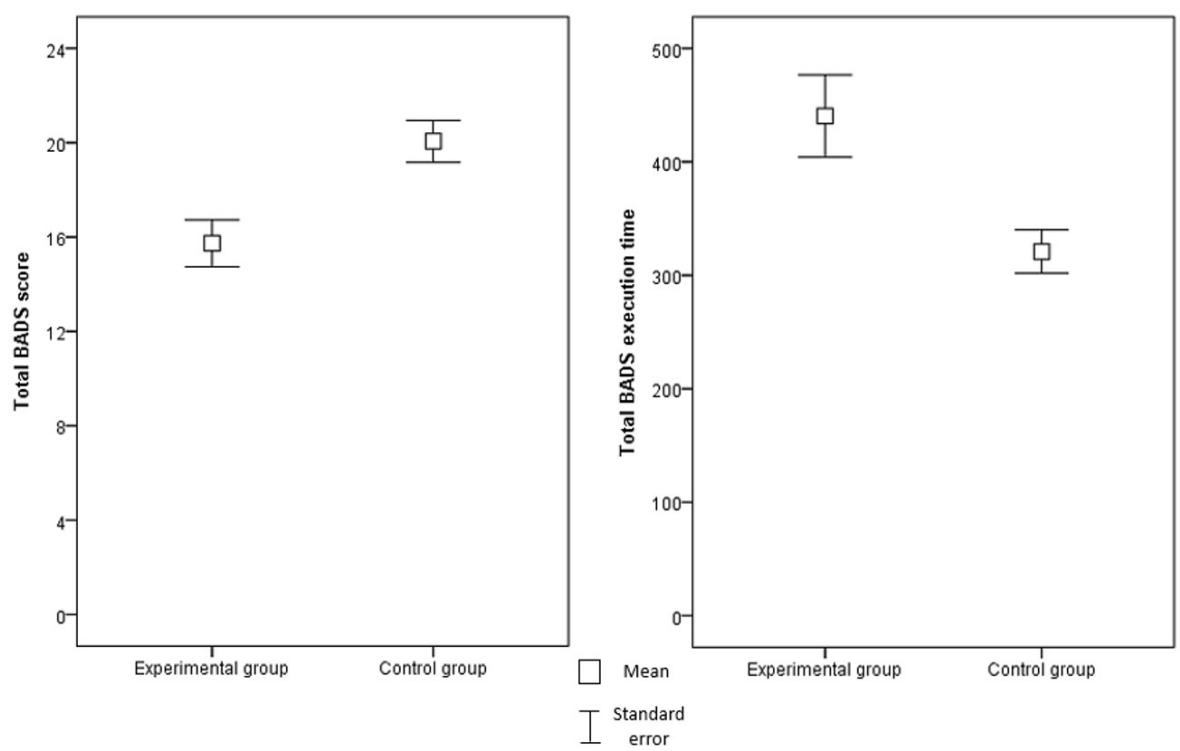

Figure 1: Means and SE of the total BADS score (on the left) and total BADS execution time, in seconds (on the right) obtained by the experimental and control groups in the BADS. Caption: BADS = Behavioural Assessment of the Dysexecutive Syndrome; SE = standard error.

Table 1: Means, SD, $t$ values, $\mathrm{p}$ values and $95 \% \mathrm{Cl}$ of the experimental and control groups of the obtained results in each BADS subtest.

\begin{tabular}{|c|c|c|c|c|c|c|}
\hline \multirow{2}{*}{ BADS subtests } & \multirow{2}{*}{$\frac{\text { Experimental group }}{\text { Mean (SD) }}$} & \multirow{2}{*}{$\begin{array}{c}\text { Control group } \\
\text { Mean (SD) }\end{array}$} & \multirow{2}{*}{$t$} & \multirow[b]{2}{*}{$\mathbf{p}$} & \multicolumn{2}{|c|}{$95 \% \mathrm{Cl}$} \\
\hline & & & & & LL & UL \\
\hline Rule Shifting Cards & $2.83(0.87)$ & $3.57(0.50)$ & -3.980 & $<0.001$ & -1.102 & -0.365 \\
\hline Action Program & $3.93(0.25)$ & $3.97(0.18)$ & -0.584 & $<0.561$ & -0.148 & 0.081 \\
\hline Key Search & $1.73(1.20)$ & $2.80(1.19)$ & -3.460 & $<0.001$ & -1.684 & -0.450 \\
\hline Temporal Judgment & $1.37(0.85)$ & $2.73(0.69)$ & -6.830 & $<0.001$ & -1.767 & -0.966 \\
\hline Zoo Map & $2.33(0.80)$ & $3.30(0.70)$ & -4.966 & $<0.001$ & -1.356 & -0.577 \\
\hline Simplified Six Elements & $3.53(0.68)$ & $3.70(0.59)$ & -1.008 & $<0.317$ & -0.498 & 0.164 \\
\hline
\end{tabular}

Caption: BADS = Behavioural Assessment of the Dysexecutive Syndrome; $\mathrm{Cl}=$ confidence interval; $\mathrm{LL}=$ lower limit; $\mathrm{SD}=$ standard deviation; $\mathrm{UL}=$ upper limit.

Table 2: Means, SD, $t$ values, $p$ values and $95 \% \mathrm{Cl}$ of the temporal performance (in seconds) of the experimental and control groups in the BADS subtests.

\begin{tabular}{|c|c|c|c|c|c|c|}
\hline \multirow{2}{*}{ BADS subtests } & \multirow{2}{*}{$\begin{array}{c}\text { Experimental group } \\
\text { Mean (SD) }\end{array}$} & \multirow{2}{*}{$\begin{array}{c}\text { Control group } \\
\text { Mean (SD) }\end{array}$} & \multirow{2}{*}{$t$} & \multirow{2}{*}{$\mathbf{p}$} & \multicolumn{2}{|c|}{$95 \% \mathrm{Cl}$} \\
\hline & & & & & LL & UL \\
\hline Rule Shifting Cards & $43.37(16.55)$ & $34.00(4.59)$ & 2.987 & $<0.004$ & 3.090 & 15.644 \\
\hline Action Program & $99.57(42.51)$ & $55.03(20.07)$ & 5.189 & $<0.001$ & 27.354 & 61.713 \\
\hline Key Search & $44.30(19.06)$ & $27.93(5.37)$ & 4.527 & $<0.001$ & 9.130 & 23.603 \\
\hline Zoo Map & $248.83(69.29)$ & $203.93(37.75)$ & 3.117 & $<0.003$ & 16.062 & 73.738 \\
\hline
\end{tabular}

Caption: BADS = Behavioural Assessment of the Dysexecutive Syndrome; Cl = confidence interval; LL = lower limit; SD = standard deviation; UL = upper limit.

both groups. Overall scores obtained by the EG $($ mean $=15.73 ; \mathrm{SD}=2.68)$ were clearly lower than those of the CG (mean $=20.07 ; \mathrm{SD}=2.38$ ), with a highly significant difference between the groups $\left(t_{(58)}=-6.63, p<0.001\right)$. On the right side of the same figure, we also show the total time (in seconds) required to execute the BADS. It was found that the time spent to perform the test presented a statistically significant difference $\left(t_{(58)}=5.95, p<0.001\right)$ between the CG (mean $=320.90, \mathrm{SD}=51.26$ ) and the EG $($ mean $=440.33, S D=97.17)$. In addition to the above-mentioned results, a detailed analysis of the 
executive performance of both groups was carried out in the BADS subtests. Table 1 shows means and standard deviations for the results obtained by the two groups in each subtest. The EG have a lower score on most subtests, except for the Action Program and Modified Six Elements Test. In the Rule Shifting Cards subtest, we found that the EG (mean $=2.83, \mathrm{SD}=0.87$ ) presented significantly lower scores $\left(t_{(58)}=-3.98, p<0.001\right)$ than the CG (mean $=3.93, \mathrm{SD}=0.25)$. Conversely, in the Action Program subtest, the EG (mean $=3.93, \mathrm{SD}=0.25$ ) showed no significant difference $\left(t_{(58)}=-0.584, p<0.561\right)$ with the $C G$ (mean $=3.97, S D=0.18)$. In the Search Key subtest, the $E G$ (mean $=1.73, S D=1.20)$ presented a statically significant difference $\left(t_{58}=-3.460, p<0.001\right)$ compared to the $C G$ (mean $=2.80, S D=1.19$ ). Likewise, a statistically significant difference $\left(t_{(58)}=-6.830, p<0.001\right)$ was found in the Temporal Judgment subtest between the $E G$ (mean $=1.37, \mathrm{SD}=0.85$ ) and the $C G$ (mean $=2.73, S D=0.69)$. The same was found in the Zoo Map subtest $\left(t_{(58)}=-4.966, \mathrm{p}<0.001\right)$, with mean of 2.33 and SD of 0.80 for the EG and mean of 3.30 and SD of 0.70 for the CG. Finally, in the Modified Six Elements Test subtest, there were no differences $\left(t_{(58)}=-1.008, p<0.317\right)$ between the $E G$ (mean $=3.53, S D=0.68$ ) and the $C G$ (mean $=3.70, \mathrm{SD}=0.59)$.

Table 2 also shows the mean values and standard deviations related to the time required for the execution of BADS subtests 1, 2, 3 and 5 in seconds. It was verified that the temporal performance obtained by the EG was significantly different from that of the $C G$ in all subtests. The EG (mean $=43.37, S D=16.55)$ required significantly more time than the $C G$ (mean $=34.00, S D=4.59$ ) to execute the Rule Shifting Cards subtest $\left(t_{(58)}=2.987, p<0.004\right)$. The same was found in the Action Program subtest $\left(t_{(58)}=5.189, p<0.001\right)$, with mean of 99.57 and SD of 42.51 for the EG and mean of 55.03 and SD of 20.07 for the CG. In the Key Search subtest, statistically significant differences $\left(t_{(58)}=4.527, \mathrm{p}<0.001\right)$ were observed between the EG (mean $=44.30, S D=19.06)$ and the CG ( mean $=27.93, S D=5.37$ ). Finally, in the Zoo Map subtest, the EG $($ mean $=248.83, S D=69.29)$ presented a significantly longer execution time $\left(t_{(58)}=3.117, p<0.003\right)$ than the CG (mean $=203.93, S D=37.75)$.

The aim of this study was also to make a description of EF in the groups according to the level of self-reported anxiety state assessed by BAI scale (Figure 2). For this purpose, the EG was distributed according to the severity of the anxious symptoms into three groups: mild anxiety group $(n=5)$, moderate anxiety group $(n=3)$, and severe anxiety group $(n=22)$. The CG scores were defined as absence of anxiety, which was used as a fourth group in the analysis.

Through Post-hoc analysis using Holm-Sidak test, we found that BADS scores are significantly lower in the group with severe anxiety $\left(t_{(58)}=-5.02, p \leq 0.001\right)$ compared to the group with no anxiety. No significant differences were found in the remaining comparisons (absence vs. mild anxiety vs. moderate anxiety). The total time to execute BADS was significantly higher in individuals with severe anxiety compared to those without anxiety $\left(t_{(58)}=146.87, p \leq 0.001\right)$; and in individuals with severe anxiety condition compared to those with mild anxiety $\left(t_{(58)}=126.94, \mathrm{p} \leq 0.004\right)$.
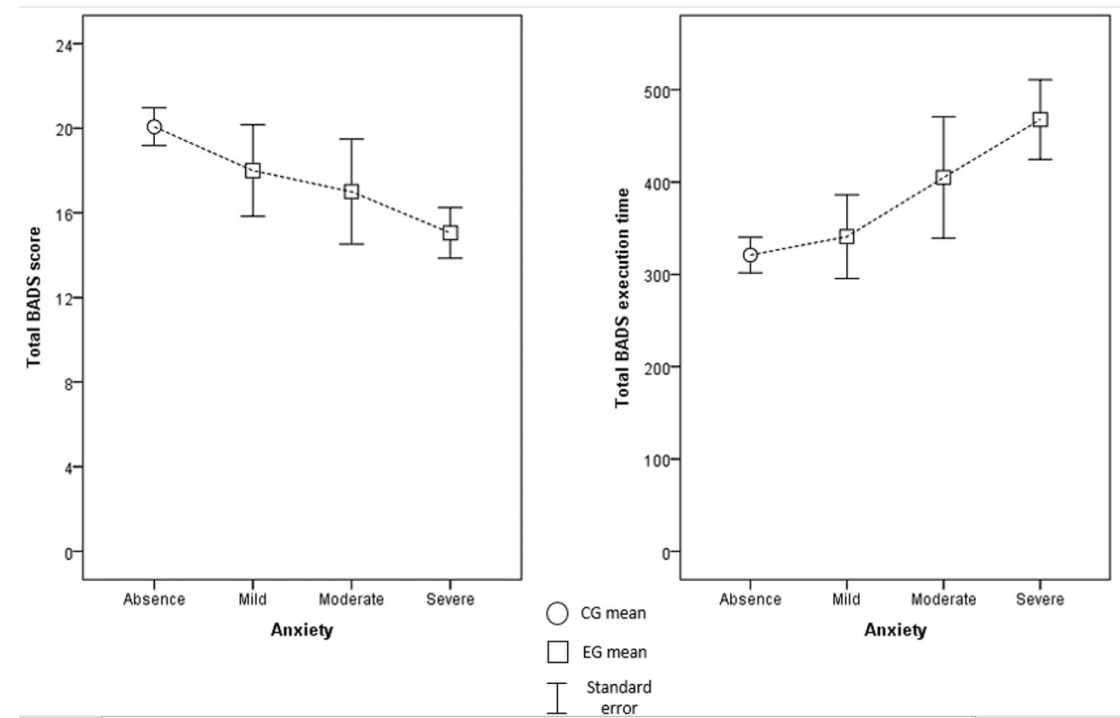

Figure 2: Mean values and standard errors for the EG and the CG relatively to the total BADS score (on the left) and total time to execute the BADS (in seconds) according to the level of anxiety verified in the BAI. Caption: BADS = Behavioural Assessment of the Dysexecutive Syndrome; BAI = Beck Anxiety Inventory; CG = control group; EG = experimental group. 


\section{DISCUSSION}

The main aim of this study was to compare EF between a sample with $A D$ and a healthy group, through a neuropsychological instrument with a higher ecological validity than the conventional tests $^{31}$. The other aim was to investigate whether there was a variation in BADS performance according to the severity of anxious symptoms.

Our results matched the initial expectations and were consistent with the results obtained in the study by Airaksinen et al. ${ }^{26}$, which stated that individuals with $A D$ present significant general EF deficits. The EG exhibited a significantly worse performance than the $\mathrm{CG}$ and required significantly more time to execute the BADS. This lower performance shows that individuals with $A D$ have a reduced capacity for mental flexibility, reduced capacity to plan efficient strategies and to monitor and solve problems, reduced judgment capacity and abstract thinking, as well as difficulties in organizing and monitoring behavior ${ }^{43}$. Furthermore, results for the time of BADS execution were consistent with our expectations. It was found that individuals with $A D$ required a longer response time, with no exception. These findings are in agreement with those by Derakshan et al. ${ }^{11}$, who found that individuals with high levels of anxiety state had longer response times in complex tasks. Total BADS score allows for the assessment of general executive performance, whereas BADS subtest scores reveal individual performance in the different dimensions of EF. Thus, contrary to expected results, the EG exhibited deficits in executive performance in most, but not all measures of the executive component. The results for BADS subtests indicate significant impairments in the subtests related to: capacity to change the previously established standard response, corresponding to an inhibition control impairment, as tested by others studies with the classic Stroop Test ${ }^{7,44,45}$; the design of action strategies, according to the functionality and probability of success; the ability to predict or estimate how much time, on average, it takes to accomplish certain events; and planning action capacity.

However, the skills that required practical problem solving seems to be preserved, contrary to the study of Joiner et al. ${ }^{46}$, as well as the capacity for temporal organization and self-monitoring. These findings may be explained by the Processing Efficiency Theory (TEP) ${ }^{47}$, which states that anxiety impairs the efficiency in performing these abilities but not performance effectiveness.

The other aim of the study was to verify whether the different levels of anxiety as assessed by the BAI presented significant effects on EF. Two recent studies ${ }^{48,49}$ concluded that the executive functioning profile varied according to the severity of the anxiety level. However, the achieved results do not corroborate with previous studies, since significant differences regarding BADS scores were observed only between the group with severe anxiety group and that without anxiety, and differences regarding temporal performance were observed only between the group with severe anxiety and those without anxiety and within mild anxiety.

This fact constituted a limitation in our study, which was caused by a small sample in the various anxiety levels; therefore, a larger sample is necessary to obtain more consistent results and generalized conclusions. Another limitation refers to the non-differentiation of $A D$ included in our sample, since the literature indicates that each disorder reflects specific deficits ${ }^{26}$ associated with differentiated brain functions ${ }^{50}$. Thus, we are looking at an upcoming study focused on the assessment of executive dysfunction in the various diagnostic subcategories using the same an ecological neuropsychological battery in order to obtain a greater prognosis of EF in daily life activities.

We conclude that there is a significant impairment in $E F$ in patients with $A D$, based on the understanding of neuropsychological battery results with high ecological validity, which allows us to infer that these individuals present deficits that are reflected in their daily tasks. This research adds an important contribution to neuropsychological research for a better understanding of the real impact of anxiety on EF. With the results achieved, we can mention the need to implement therapies and rehabilitation programs and therapies in order to overcome functioning deficits.

\section{Acknowledgements}

We thank all the participants who collaborated in this study and also to the psychology consulting service of the student support department for all collaboration.

\section{Conflicts of interest}

The authors declare no conflicts of interest. 


\section{REFERENCES}

1. Kessler RC, Berglund P, Demler O, Jin R, Merikangas KR, Walters EE. Lifetime prevalence and age-of-onset distributions of DSM-IV disorders in the national comorbidity survey replication. Arch Gen Psychiatry. 2005;62:593-602.

2. Kadri N, Agoub M, El Gnaoui S, Berrada S, Moussaoui D. Prevalence of anxiety disorders: a populationbased epidemiological study in metropolitan area of Casablanca, Morocco. Ann Gen Psychiatry. 2007;6:6.

3. Bandelow B, Michaelis S Epidemiology of anxiety disorders in the 21st century. Dialogues Clin Neurosci. 2015;17:327-35.

4. Clark DA, Beck AT. Terapia cognitiva para os transtornos de ansiedade: ciência e prática. Porto Alegre: Artmed; 2012.

5. Bauer S. Da ansiedade à depressão: da psicofarmacologia à psicoterapia. São Paulo: Livro Pleno; 2002.

6. Allen AJ, Leonard H, Swedo SE. Current knowledge of medications for the treatment of childhood anxiety disorders. J Am Acad Child Adolesc Psychiatry. 1995;34:976-86.

7. Eysenck MW, Derakshan N, Santos R, Calvo MG. Anxiety and cognitive performance: attentional control theory. Emotion. 2007;7:336-53.

8. Eysenck MW. Anxiety: the cognitive perspective. Hove: Psychology Press; 1992.

9. Ansari TL, Derakshan N. Anxiety impairs inhibitory control but not volitional action control. Cogn Emotion. 2010;24:241-54.

10. Derakshan N, Ansari TL, Hansard M, Shoker L, Eysenck MW. Anxiety, inhibition, efficiency, and effectiveness: an investigation using antisaccade task. Exp Psychol. 2009;56:48-55.

11. Derakshan N, Smyth S, Eysenck MW. Effects of state anxiety on performance using a task-switching paradigm: an investigation of attentional control theory. Psychon Bull Rev. 2009;16:112-7.

12. Aron AR. Progress in executivefunction research. Curr Dir Psychol Sci. 2008:17:124-9.
13. Wagner GP, Trentini CM. Assessing executive functions in older adults: a comparison between the manual and the computer-based versions of the Wisconsin Card Sorting Test. Psychol Neurosci. 2009;2:195-8.

14. Baddeley A. The central executive: a concept and some misconceptions. $J$ Int Neuropsychol Soc. 1998;4:523-6.

15. Huizinga M, Dolan CV, van der Molen MW. Age-related change in executive function: developmental trends and a latent variable analysis. Neuropsychologia. 2006;44:2017-36.

16. Miyake A, Friedman NP, Emerson MJ, Witzki AH, Howerter A, Wager TD. The unity and diversity of executive functions and their contributions to complex "Frontal Lobe" tasks: a latent variable analysis. Cognit Psychol. 2000;41:49-100.

17. Stuss DT, Knight RT. Principles of frontal lobe function. 3rd ed. New York: Oxford University Press; 2013.

18. Roberts AC, Robbins TW, Weiskrantz L. The prefrontal cortex: executive and cognitive functions. New York: Oxford University Press; 1998.

19. Lezak MD, Howieson DB, Loring DW. Neuropsychological assessment. New York: Oxford University Press; 2004.

20. Banhato EFC, Nascimento E. Função executiva em idosos: um estudo utilizando subtestes da escala WAISIII. Psico-USF. 2007;12:65-73.

21. Kim MJ, Gee DG, Loucks RA, Davis FC, Whalen PJ. Anxiety dissociates dorsal and ventral medial prefrontal cortex functional connectivity with the amygdala at rest. Cereb Cortex. 2010;21:1667-73.

22. Davidson RJ, Abercrombie $\mathrm{H}$, Nitschke JB, Putnam K. Regional brain function, emotion and disorders of emotion. Curr Opin Neurobiol. 1999;9:228-34.

23. Luu P, Tucker DM, Derryberry D. Anxiety and the motivational basis of working memory. Cognit Ther Res. 1998;22:577-94.

24. Sapir S, Aronson AE. The relationship between psychopathology and speech and language disorders in neurologic patients. J Speech Hear Disord. 1990:55:503-9
25. Park J, Wood J, Bondi C, Del Arco A, Moghaddam B. Anxiety evokes hypofrontality and disrupts rulerelevant encoding by dorsomedial prefrontal cortex neurons. J Neurosci. 2016;36:3322-35.

26. Airaksinen E, Larsson M, Forsell Y. Neuropsychological functions in anxiety disorders in populationbased samples: evidence of episodic memory dysfunction. J Psychiatr Res. 2005;39:207-14.

27. Santos Barbosa MF, Coelho Monteiro LM. Recurrent criminal behavior and executive dysfunction. Span $J$ Psychol. 2008;11:259-65.

28. Tirapu-Ustarróz J, Muñoz-Céspedes JM, Pelegrin-Valero C. Funciones ejecutivas: necesidad de una integración conceptual. Rev Neurol. 2002;34:673-85.

29. Wilson B, Alderman N, Burguess P, Emslie H, Evans J. Behavioural assessment of the dysexecutive syndrome (BADS). London: Thames Valley Test Company; 1996.

30. Burgess PW, Alderman N, Evans J, Emslie $\mathrm{H}$, Wilson BA. The ecological validity of tests of executive function. $J$ Int Neuropsychol Soc. 1998;4:547-58.

31. Norris G, Tate RL. The Behavioural Assessment of the Dysexecutive Syndrome (BADS): ecological, concurrent and construct validity. Neuropsychol Rehabil. 2000;10:33-45.

32. Silva T, Monteiro L, Lopes E. INECO frontal screening: an instrument to assess executive dysfunction in schizofrenia. Span J Psychol. 2014;17:E19.

33. Almeida RMC, Macedo G, Lopes E, Monteiro L. BADS-C instrument: an ecological perspective of the executive functions in children with attention deficit hyperativity disorder. Acta Neuropsychol. 2014;12:293-303.

34. Santos Barbosa MF, Coelho Monteiro LM. Recurrent criminal behavior and executive dysfunction. Span J Psychol. 2008;11:259-65.

35. Nunes D, Monteiro LC, Lopes E. Executive dysfunction in depression: a study of prefrontal dysfunction. Acta Neuropsychol. 2012;10:499-508. 
36. Medeiros M, Lopes E, Macedo G, Monteiro L. Coping, executive functions, inhibitory control and decision-making in a sample of depressed suicidal patients. Clin Biomed Res. 2014;34:287-96.

37. Almeida T, Monteiro LC. Executive functions and decision making regarding drug addicts in abstinence. Acta Neuropsychol. 2012;12:387-400.

38. Beck AT, Epstein N, Brown G, Steer RA. An inventory for measuring clinical anxiety: psychometric properties. $J$ Consult Clin Psychol. 1988;56:893-7.

39. Cunha JA. Manual da versão em português das escalas Beck. São Paulo: Casa do Psicólogo; 2001.

40. Quintão SR. Validación de la versión portuguesa de la escala de ansiedad de Beck-BAl [tesis]. Salamanca: Universidad de Salamanca; 2010. [cited 2017 Sept 5]. Available from: http://hdl.handle.net/10366/76505
41. Barbosa F, Peixoto B, Silveira C. Behavioral Assessment of the Dysexecutive Syndrome (BADS): dados normativos portugueses e indicadores psicométricos. Salud Ment. 2011;13:21-7.

42. Pestana MH, Gageiro JN. Análise de dados para ciências sociais: a complementaridade do SPSS. 3rd ed. Lisboa: Editora Sílabo; 2003.

43. Spreen O, Strauss E. A compendium of neuropsychological tests: administration, norms and commentary. 2nd ed. New York: Oxford University Press; 1998.

44. Derryberry D, Reed MA. Anxietyrelated attentional biases and their regulation by attentional control. $J$ Abnorm Psychol. 2002;111:225-36.

45. Visu-Petra L, Miclea M, VisuPetra G. Individual differences in anxiety and executive functioning: a multidimensional view. Int J Psychol. 2013;48:649-59.
46. Joiner TE, Vohs KD, Rudd MD, Schmidt NB, Pettit JW. Problemsolving and cognitive scars in mood and anxiety disorders: the sting of mania. J Soc Clin Psychol. 2003;22:192-212.

47. Eysenck MW, Calvo MG. Anxiety and performance: the processing efficiency theory. Cogn Emotion. 1992;6:409-34.

48. O'Donnell PS. Executive functioning profiles and test anxiety in college students. J Psychoed Assess. 2016;35(5):447-59.

49. Fujii Y, Kitagawa N, Shimizu Y, Mitsui N, Toyomaki A, Hashimoto $\mathrm{N}$, et al. Severity of generalized social anxiety disorder correlates with low executive functioning. Neurosci Lett. 2013;543:42-6

50. Engel K, Bandelow B, Gruber O, Wedekind D. Neuroimaging in anxiety disorders. J Neural Transm. 2009;116:703-16.

Received: Sept 05, 2017 Accepted: Jan 24, 2018 